\title{
RBEP
}

\section{As propostas de políticas/ações afirmativas das universidades públicas e as políticas/ações de permanência nos ordenamentos legais}

Letícia Pereira Sousa

Écio Antônio Portes

\section{Resumo}

Aborda os aspectos legais do processo de implantação das políticas/ ações afirmativas nas universidades federais. Para tanto, revisita as discussões favoráveis às ações afirmativas em Carvalho (2003), Gomes (2005) e Munanga (2003) e as que as criticam, em Maggie e Fry (2002), Maio e Santos (2007), entre outros. Busca, mediante a análise documental, entender como as políticas/ações afirmativas funcionam e que trato é dado às políticas de assistência/permanência. As análises efetuadas evidenciaram a implantação de diferentes políticas/ações afirmativas no que diz respeito ao ingresso dos jovens pobres negros e brancos. Contudo, os dados mostraram que as políticas de assistência/permanência só figuram como prioridade em um conjunto restrito de ordenamentos, em função dos custos econômicos necessários para sua implantação.

Palavras-chave: acesso ao ensino; ação política; política governamental; condições socioeducacionais; sociologia da educação. 


\section{Abstract \\ The public universities affirmative actions and the permanence policies in the legal system}

The study focused on the legal aspects of the federal universities affirmative policies implementation. In this sense, it revises the work of Carvalho (2003), Gomes (2005) and Munanga (2003) as well as some critics in the work of Maggie and Fry (2002), Maio and Santos (2007) and others. It aims at the understanding of the permanence policies/actions process through documental analysis. The analysis pointed out some differences concerning poor black youths and whites' access to higher education. However, the data analysis showed that these policies just appear as a priority in some legal systems as they suffer economical restraints to their implementation.

Keywords: access; political action; governmental policies; socioeducational conditions; sociology of education.

\section{Introdução}

O presente trabalho cuidou de compreender os aspectos legais do processo de implantação das políticas/ações afirmativas voltadas para o ingresso nas universidades federais. Para isso, buscamos analisar, no conjunto de ordenamentos ${ }^{1}$ das universidades que adotaram políticas/ações afirmativas, como esse sistema funciona. Verificamos ainda nesses ordenamentos o trato que é dado à questão das políticas de assistência/permanência.

O termo ação afirmativa, de acordo com Domingues (2005), foi criado em 1963, nos Estados Unidos, pelo então presidente J. F. Kennedy, para nomear o conjunto de políticas públicas e privadas para o combate à discriminação racial. No Brasil, segundo Carvalho (2003), a discussão acerca da implantação de ações de caráter reparatório a favor da população negra começou com o Jornal Quilombo, publicado nos anos de 1949 e 1950 pelo grupo de Abdias do Nascimento - importante intelectual relacionado à questão do negro na sociedade -, e já trazia a ideia de entrada

${ }^{1}$ Consultamos um conjunto diverso de documentos resolução, parecer, decisão, deliberação, editais, e-mail Dessa forma, utilizaremos o termo ordenamento englobando essas diversas denominações, o que parece ser suficiente para os nossos propósitos e ainda para amenizar a linguagem. dos estudantes negros na educação pública e privada, em todos os níveis de ensino, como bolsistas do Estado. Como se pode ver ainda em Tales de Azevedo (1996), essa discussão não é recente.

Cabe ressaltar que as ações afirmativas não se reduzem à implantação de cotas raciais nas universidades como os meios de comunicação de massa têm divulgado. As cotas - reserva de um percentual de vagas para o grupo que se pretende promover - representam uma das possíveis 
estratégias para o desenvolvimento dessas ações. Portanto, existem outras formas de políticas/ações afirmativas destinadas a facilitar a entrada de determinados grupos no ensino superior público. Pela definição de Oliven (2007), as ações afirmativas são um conjunto de políticas públicas que visam proteger minorias que tenham sido discriminadas em determinada sociedade, além de buscarem promover sua ascensão a postos de comando. Ao realizar a junção de vários conceitos, Moehlecke (2002) coloca as ações afirmativas como reparatórias, compensatórias e que buscam a correção de uma situação de discriminação e desigualdade em que se encontram determinados grupos sociais. De acordo com a autora, os principais campos em que foram adotadas as ações afirmativas são o mercado de trabalho, a política e a educação superior, beneficiando os representantes de minorias raciais e étnicas e as mulheres.

A discussão acerca das políticas/ações afirmativas ganhou destaque no cenário brasileiro, principalmente na mídia, após a III Conferência Mundial de Combate ao Racismo, Discriminação Racial, Xenofobia e Intolerância Correlata, realizada em Durban, na África do Sul, de 31 de agosto a 7 de setembro de 2001. Nessa Conferência, a delegação oficial brasileira comprometeu-se a lutar contra a discriminação racial e propôs a adoção de ações afirmativas a favor da população afrodescendente, inclusive a de cotas para negros nas universidades públicas. Antes da realização da Conferência de Durban, o Brasil não tinha políticas públicas de caráter étnico-racial para a entrada desses sujeitos nas universidades públicas e, de certa forma, ignorava os resultados de grandes pesquisas que apresentavam os negros em situações de exclusão devido aos velados preconceitos raciais. Segundo Guimarães (2003, p. 252), ao se apresentar internacionalmente como um país livre da questão racial, o Brasil era "reiteradamente lembrado das suas desigualdades raciais, facilmente demonstráveis pelas estatísticas oficiais, sem poder apresentar em sua defesa um histórico de políticas de combate a essas desigualdades." Nesse sentido, sem deixar de considerar as pressões da classe média negra e do movimento negro, esse autor afirma que foi procurando uma saída estratégica e política que o então presidente Fernando Henrique Cardoso se empenhou em trazer a questão das ações afirmativas para o debate nacional. Assim, na Conferência de Durban, a delegação brasileira colocou a "democracia racial" como um mito e assumiu as desigualdades de caráter racial, além de se comprometer a revertê-las por meio das ações afirmativas.

Contudo, de acordo com Yvonne Maggie e Peter Fry, em artigo publicado em 2002, antes da Conferência de Durban foram realizados três seminários com o intuito de preparar a posição do Brasil na Conferência. Entretanto, poucos, além de ativistas negros, souberam ou participaram, o que impossibilitou a discussão do tema de forma mais abrangente. Assim, segundo os autores, o comprometimento do Brasil com a adoção de políticas afirmativas se deu sem uma participação efetiva da população, fato que até hoje gera polêmica, principalmente entre os defensores e aqueles que questionam a implementação das ações afirmativas. 
Para a compreensão deste trabalho, revisitamos as discussões polarizadas acerca da implementação das ações afirmativas. Aqueles que se posicionam contra as ações, sob a forma de cotas e bônus, utilizam o princípio da igualdade política e jurídica dos cidadãos, presente na Constituição de 1988, como uma forte base para suas argumentações as cotas, juntamente com o bônus, representariam uma ameaça a esse princípio. Outro ponto marcante é a dificuldade da utilização desse sistema no Brasil devido à grande mestiçagem da população, o que poderia gerar fraude por parte dos alunos brancos. Além do mais, sua utilização poderia estimular o preconceito e prejudicar valores, como orgulho e dignidade da população negra. Segundo Goldemberg e Durham (2007), as cotas representariam um retrocesso, já que, pela primeira vez na República, haverá a distinção legal entre negros e brancos. Os opositores das cotas também utilizam argumentos baseados na ciência, como aponta Pena (2007, p. 45), ao afirmar que, "do ponto de vista biológico, raças humanas não existem". De acordo com Benjamin (2007, p. 33), o que determina a cor de uma pessoa é a quantidade de melanina na pele. Assim, ele afirma que "não somos nem brancos nem negros, somos mestiços".

Para alguns autores, como Maggie e Fry (2002), as cotas contrariam o arracismo relacionado ao Brasil, uma vez que rompem com a ideologia que define nosso País como sendo de misturas. Segundo eles, as cotas também vão contra nossa Carta Magna e poderiam retomar um sistema de classificação racial que geraria uma bipolarização, pelo qual as pessoas devem ser classificadas entre negros e brancos, ou seja, entre aqueles que têm direito às cotas e os que não têm. Os autores afirmam que a reserva de vagas para negros no ensino superior terá consequências apenas para os "brancos" das camadas populares, uma vez que serão eles os excluídos dessa reserva e em nada será afetada a elite branca. Assim, contestam ainda a eficácia de uma política que visa "corrigir" as desigualdades de qualquer ordem por meio de uma "política de custo zero" e chamam também a atenção para a celebração do conceito de "raça", sem o qual o racismo não pode existir.

Noutro extremo, Munanga (2003) refuta alguns desses argumentos. Quanto a possíveis fraudes na autodeclaração dos candidatos ao exame vestibular, acredita que, pela força do ideal de branqueamento, os alunos brancos não tentem tal estratégia, e sim utilizem argumentos com base na igualdade perante a lei. No que diz respeito ao orgulho negro e ao possível racismo advindo das ações afirmativas, expõe que as cotas são uma política compensatória e que não estimulariam o preconceito, porque ele já existe.

Para aqueles que se posicionam a favor das políticas/ações afirmativas, a adoção de cotas não discordaria do direito universal da Constituição de 1988, mas sim enfatizaria que esse direito é insuficiente para atender a grupos étnicos excluídos e discriminados racialmente

${ }^{2}$ Pesquisa Nacional por Amostra de Domicílios (Pnad) de 1992 a 1999 do Instituto Brasileiro de Geografia e Estatística (IBGE). (Gomes, 2005). Outro ponto destacado pelos defensores das cotas é a situação de exclusão social em que vive o negro no Brasil. Nesse sentido, Tragtenberg (2002) apresenta dados da Pnad/IBGE ${ }^{2}$ que mostram, entre 
outras informações, ser o salário médio do negro a metade do salário do branco e que as taxas de analfabetismo caem menos para a população negra em relação à branca, afirmando, assim, estarmos diante de um "apartheid social disfarçado". Segundo Munanga (2003), as cotas seriam um instrumento transitório, até o amadurecimento da sociedade, e possibilitariam o acesso dos negros a posições majoritariamente brancas. Para ilustrar sua afirmação, o autor aponta a porcentagem de alunos negros no ensino superior, $2 \%$, comparada ao contingente branco, que representa 97\% dos estudantes.

Para Gomes (2005), as cotas são insuficientes para colocar fim ao racismo. Nesse sentido, diz ser necessário que elas aconteçam dentro de políticas mais amplas, a médio e longo prazos, inclusive com o desenvolvimento de políticas de permanência que garantam aos negros, após o acesso, a conclusão de seus cursos. Ainda nessa linha, Tragtenberg (2003) declara que, em raros casos, a questão da permanência dos pobres, principalmente negros, foi encarada seriamente e que essa população precisa de assistência financeira e apoio pedagógico para concluir seus cursos. As pesquisas da área da Sociologia da Educação que tratam das trajetórias de estudantes das camadas populares que ingressam nas universidades públicas confirmam a necessidade de instalação de programas de permanência, mas esse discurso parece não ter ressonância no desenvolvimento de políticas públicas para esse fim (Portes, 2001).

Feita essa incursão sobre as diferentes posições no campo em questão, a hipótese que fundamenta esta pesquisa é que a entrada de estudantes pobres, negros e brancos, no ensino superior público, principalmente em seus cursos mais reservados aos herdeiros culturais, por si só não é suficiente para garantir a esses alunos a "permanência" e a saída em bons termos, visto que eles não vêm conseguindo se livrar dos constrangimentos culturais, econômicos, pedagógicos e psicológicos produzidos no interior da universidade, como demonstraram os estudos de Almeida (2007), Lacerda (2006), Piotto (2007, 2008), Portes (1993, 2000, 2001), Portes e Cruz (2007), Portes e Sousa (2009), Souza e Silva (1999) e Viana (1998, 2007).

Este trabalho se justifica, pois temos mostrado com as nossas pesquisas (Portes, 2001) que, se a presença do estudante pobre, inclusive o negro, no ensino superior brasileiro data desde a criação dos cursos jurídicos em 1827 e se acentua com a instituição e a ampliação do aparato desse nível de ensino no século 20, a permanência desse tipo de estudante, por outro lado, tem-se dado à revelia do Estado. Para permanecer no sistema superior de ensino público de qualidade, o estudante pobre desenvolve um conjunto significativo de estratégias, pessoais e coletivas, materiais e simbólicas, pois ele não tem visibilidade no interior dos cursos e é visto na figura de um acadêmico universal.

Nossos estudos (Portes, 2003) mostram que, mesmo em espaços como o da Universidade Federal de Minas Gerais (UFMG), onde se construíram condições de permanência dos estudantes pobres no seu interior desde a 
sua fundação em 1927, esses alunos não têm se livrado do fantasma do constrangimento econômico, ainda que essa universidade tenha criado um aparato profissional de assistência a eles, independentemente da condição étnico-racial.

\section{Aspectos metodológicos}

A proposta metodológica desenvolvida nesta pesquisa se apoiou na revisão da literatura sobre o tema tratado, declaradamente os artigos que cuidam das políticas e ações afirmativas para negros ou estudantes pobres e que se ocupam das questões atinentes à permanência/assistência, como apontado na introdução deste trabalho e na leitura de outras obras indicadas nas referências bibliográficas. Apoiou-se, ainda, em coleta, leitura, tratamento e análise da documentação. Cabe ressaltar que o conjunto de ordenamentos que fundamentou este estudo foi coletado durante o período de agosto a dezembro de 2009.

Trabalhamos com documentos de 59 universidades, de acordo com a lista das Instituições Federais de Ensino Superior (Ifes) disponibilizada no site da Associação Nacional dos Dirigentes das Instituições Federais de Ensino Superior (Andifes), pois a listagem das Ifes disponível no site do Ministério da Educação (MEC) encontrava-se incompleta e faltava, inclusive, o nome da instituição de origem dos pesquisadores, no caso, a Universidade Federal de São João del-Rei (UFSJ).

Nosso interesse inicial era verificar apenas nas resoluções das universidades que adotaram as políticas/ações afirmativas as diferentes propostas e o trato dado às questões relacionadas à permanência/ assistência daqueles que pudessem se beneficiar das políticas de acesso implementadas.

Devido às dificuldades encontradas, ampliamos a coleta de dados para além das resoluções e passamos a abranger edital do vestibular, manual do candidato, plano de metas e e-mails trocados por nós com representantes das instituições, enfim, incluímos documentos que versavam sobre a implantação das políticas/ações afirmativas nas universidades. Mesmo assim, essa estratégia não esgotou as nossas dificuldades, pois sabemos que algumas universidades oferecem políticas de permanência (como é o caso da UFMG), embora nos documentos consultados nada disso conste. Queremos com isso afirmar que os números por nós apresentados podem sofrer pequenas variações, mas não a ponto de negar aquilo que a grandeza deles expressa com clareza.

Após a análise documental e a organização do material coletado, fizemos a separação por categorias e, para facilitar o manuseio e a visualização dos ordenamentos consultados, elaboramos o Quadro 1, no qual constam a identificação dada pelos pesquisadores aos documentos consultados, a sigla da universidade, o tipo de ação afirmativa adotada por ela e a natureza do documento analisado. As universidades que não adotam ações afirmativas não aparecem no Quadro 1. 


\section{Quadro 1 - Instituições Federais de Ensino Superior que possuem ações} afirmativas

\begin{tabular}{|c|c|c|c|}
\hline Universidade & Identificação & Tipo de Ação & Ordenamento \\
\hline $\begin{array}{l}\text { Centro Federal de } \\
\text { Educação Tecnológica da } \\
\text { Bahia (Cefet-BA) }\end{array}$ & 17 & $\begin{array}{c}\text { reserva } \\
\text { sociorracial }\end{array}$ & $\begin{array}{l}\text { Resolução } \\
\text { no 10/2006 }\end{array}$ \\
\hline $\begin{array}{l}\text { Universidade Federal do } \\
\text { Rio Grande (Furg) }\end{array}$ & 32 & $\begin{array}{c}\text { bônus } \\
\text { sociorracial }\end{array}$ & $\begin{array}{c}\text { Resolução } \\
\text { nº 019/2009 }\end{array}$ \\
\hline $\begin{array}{l}\text { Universidade Federal do } \\
\text { ABC (UFABC) }\end{array}$ & 20 & $\begin{array}{c}\text { reserva } \\
\text { sociorracial }\end{array}$ & $\begin{array}{l}\text { Resolução } \\
\text { Consep } \\
\text { no 32/2009 }\end{array}$ \\
\hline $\begin{array}{l}\text { Universidade Federal de } \\
\text { Alagoas (Ufal) }\end{array}$ & 12 & $\begin{array}{l}\text { reserva } \\
\text { racial }\end{array}$ & $\begin{array}{l}\text { Resolução } \\
\text { Cepe } \\
\text { no 09/2004 }\end{array}$ \\
\hline $\begin{array}{l}\text { Universidade Federal da } \\
\text { Bahia (UFBA) }\end{array}$ & 22 & $\begin{array}{c}\text { reserva } \\
\text { sociorracial }\end{array}$ & $\begin{array}{l}\text { Resolução } \\
\text { no 01/2004 }\end{array}$ \\
\hline $\begin{array}{l}\text { Universidade Federal do } \\
\text { Espírito Santo (Ufes) }\end{array}$ & 01 & $\begin{array}{l}\text { reserva } \\
\text { social }\end{array}$ & $\begin{array}{l}\text { Resolução } \\
\text { no 23/2009 }\end{array}$ \\
\hline $\begin{array}{l}\text { Universidade Federal } \\
\text { Fluminense (UFF) }\end{array}$ & 30 & bônus social & 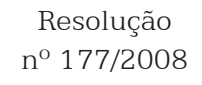 \\
\hline $\begin{array}{l}\text { Universidade Federal de } \\
\text { Goiás (UFG) }\end{array}$ & 27 & $\begin{array}{c}\text { reserva } \\
\text { sociorracial }\end{array}$ & $\begin{array}{c}\text { Anexo da } \\
\text { Resolução } \\
\text { Consuni } \\
\text { no 29/2008 }\end{array}$ \\
\hline $\begin{array}{l}\text { Universidade Federal } \\
\text { da Grande Dourados } \\
\text { (UFGD) }\end{array}$ & 06 & $\begin{array}{l}\text { reserva } \\
\text { social }\end{array}$ & $\begin{array}{c}\text { Edital } \\
\text { Prograd } \\
\mathrm{n}^{\circ} 15 / 2009\end{array}$ \\
\hline $\begin{array}{l}\text { Universidade Federal de } \\
\text { Juiz de Fora (UFJF) }\end{array}$ & 14 & $\begin{array}{c}\text { reserva } \\
\text { sociorracial }\end{array}$ & $\begin{array}{l}\text { Resolução } \\
\text { no 16/2004 }\end{array}$ \\
\hline $\begin{array}{l}\text { Universidade Federal do } \\
\text { Maranhão (UFMA) }\end{array}$ & 21 & $\begin{array}{c}\text { reserva } \\
\text { sociorracial }\end{array}$ & $\begin{array}{c}\text { Edital } \\
\text { no }^{\circ} 95 / 2008\end{array}$ \\
\hline $\begin{array}{l}\text { Universidade Federal de } \\
\text { Minas Gerais (UFMG) }\end{array}$ & 31 & $\begin{array}{c}\text { bônus } \\
\text { sociorracial }\end{array}$ & Edital 2010 \\
\hline $\begin{array}{l}\text { Universidade Federal de } \\
\text { Ouro Preto (Ufop) }\end{array}$ & 03 & $\begin{array}{l}\text { reserva } \\
\text { social }\end{array}$ & $\begin{array}{c}\text { Resolução } \\
\text { Cepe } \\
\text { no 3.270/2008 }\end{array}$ \\
\hline $\begin{array}{l}\text { Universidade Federal do } \\
\text { Pará (UFPA) }\end{array}$ & 19 & $\begin{array}{c}\text { reserva } \\
\text { sociorracial }\end{array}$ & $\begin{array}{c}\text { Resolução } \\
\mathrm{n}^{\circ} 3.361 / 2005\end{array}$ \\
\hline $\begin{array}{l}\text { Universidade Federal de } \\
\text { Pernambuco (UFPE) }\end{array}$ & 35 & bônus social & $\begin{array}{c}\text { Resolução } \\
\text { nº 03/2009 }\end{array}$ \\
\hline $\begin{array}{l}\text { Universidade Federal do } \\
\text { Piauí (UFPI) }\end{array}$ & 02 & $\begin{array}{c}\text { reserva } \\
\text { social }\end{array}$ & $\begin{array}{c}\text { Edital } \\
\text { n}^{\circ} 19 / 2009\end{array}$ \\
\hline
\end{tabular}


(continuação)

\begin{tabular}{|c|c|c|c|}
\hline Universidade & Identificação & Tipo de Ação & Ordenamento \\
\hline $\begin{array}{l}\text { Universidade Federal do } \\
\text { Paraná (UFPR) }\end{array}$ & 13 & $\begin{array}{c}\text { reserva } \\
\text { sociorracial }\end{array}$ & $\begin{array}{l}\text { Resolução } \\
\text { no } 17 / 2007\end{array}$ \\
\hline $\begin{array}{l}\text { Universidade Federal } \\
\text { Rural da Amazônia (Ufra) }\end{array}$ & 16 & $\begin{array}{c}\text { reserva } \\
\text { sociorracial }\end{array}$ & $\begin{array}{c}\text { Edital } \\
\text { no } 24 / 2009\end{array}$ \\
\hline $\begin{array}{l}\text { Universidade Federal } \\
\text { do Recôncavo da Bahia } \\
\text { (UFRB) }\end{array}$ & 18 & $\begin{array}{c}\text { reserva } \\
\text { sociorracial }\end{array}$ & 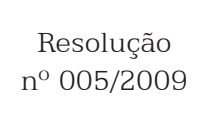 \\
\hline $\begin{array}{l}\text { Universidade Federal } \\
\text { do Rio Grande do Sul } \\
\text { (UFRGS) }\end{array}$ & 24 & $\begin{array}{c}\text { reserva } \\
\text { sociorracial }\end{array}$ & $\begin{array}{c}\text { Decisão } \\
\mathrm{n}^{0} 134 / 2007\end{array}$ \\
\hline $\begin{array}{l}\text { Universidade Federal } \\
\text { do Rio Grande do Norte } \\
\text { (UFRN) }\end{array}$ & 34 & bônus social & Edital 2010 \\
\hline $\begin{array}{l}\text { Universidade Federal } \\
\text { Rural de Pernambuco } \\
\text { (UFRPE) }\end{array}$ & 33 & bônus social & $\begin{array}{c}\text { Edital } \\
\text { no } 93 / 2009\end{array}$ \\
\hline $\begin{array}{l}\text { Universidade Federal de } \\
\text { Roraima (UFRR) }\end{array}$ & 37 & $\begin{array}{l}\text { processo } \\
\text { seletivo } \\
\text { específico }\end{array}$ & $\begin{array}{l}\text { Resolução } \\
\text { Cepe } \\
\text { no 008/2007 }\end{array}$ \\
\hline $\begin{array}{l}\text { Universidade Federal } \\
\text { Rural do Rio de Janeiro } \\
\text { (UFRRJ) }\end{array}$ & 29 & bônus social & 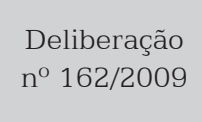 \\
\hline $\begin{array}{l}\text { Universidade Federal de } \\
\text { Sergipe (UFS) }\end{array}$ & 15 & $\begin{array}{c}\text { reserva } \\
\text { sociorracial }\end{array}$ & $\begin{array}{l}\text { Resolução } \\
\text { Conepe } \\
\text { no 80/2008 }\end{array}$ \\
\hline $\begin{array}{l}\text { Universidade Federal de } \\
\text { Santa Catarina (UFSC) }\end{array}$ & 25 & $\begin{array}{c}\text { reserva } \\
\text { sociorracial }\end{array}$ & $\begin{array}{l}\text { Resolução } \\
\text { CUN } \\
\text { no } 008 / 2007\end{array}$ \\
\hline $\begin{array}{l}\text { Universidade Federal de } \\
\text { São Carlos (UFSCar) }\end{array}$ & 26 & $\begin{array}{c}\text { reserva } \\
\text { sociorracial }\end{array}$ & $\begin{array}{c}\text { Resolução } \\
\text { Consuni } \\
\text { no 541/2007 }\end{array}$ \\
\hline $\begin{array}{l}\text { Universidade Federal de } \\
\text { São João del-Rei (UFSJ) }\end{array}$ & 08 & $\begin{array}{l}\text { reserva } \\
\text { social }\end{array}$ & $\begin{array}{l}\text { Resolução } \\
\text { n 22/2009 }\end{array}$ \\
\hline $\begin{array}{l}\text { Universidade Federal de } \\
\text { Santa Maria (UFSM) }\end{array}$ & 28 & $\begin{array}{c}\text { reserva } \\
\text { sociorracial }\end{array}$ & $\begin{array}{c}\text { Resolução } \\
\mathrm{n}^{\circ} 011 / 2007\end{array}$ \\
\hline $\begin{array}{l}\text { Universidade Federal do } \\
\text { Tocantins (UFT) }\end{array}$ & 11 & $\begin{array}{l}\text { reserva } \\
\text { racial }\end{array}$ & $\begin{array}{c}\text { Resolução } \\
\text { Consepe } \\
\text { n 3A/2004 }\end{array}$ \\
\hline $\begin{array}{l}\text { Universidade Federal } \\
\text { do Triângulo Mineiro } \\
\text { (UFTM) }\end{array}$ & 38 & bônus social & $\begin{array}{c}\text { Edital } \\
\mathrm{n}^{\circ} 08 / 2009\end{array}$ \\
\hline
\end{tabular}


(conclusão)

\begin{tabular}{|c|c|c|c|}
\hline Universidade & Identificação & Tipo de Ação & Ordenamento \\
\hline $\begin{array}{l}\text { Universidade Federal de } \\
\text { Uberlândia (UFU) }\end{array}$ & 07 & $\begin{array}{l}\text { reserva } \\
\text { social }\end{array}$ & $\begin{array}{l}\text { Resolução } \\
\text { n }^{\circ} 20 / 2008\end{array}$ \\
\hline $\begin{array}{l}\text { Universidade Federal de } \\
\text { Viçosa (UFV) }\end{array}$ & 36 & bônus social & $\begin{array}{l}\text { Manual do } \\
\text { Candidato- } \\
\text { Vestibular } \\
2010\end{array}$ \\
\hline $\begin{array}{l}\text { Universidade Federal dos } \\
\text { Vales do Jequitinhonha e } \\
\text { Mucuri (UFVJM) }\end{array}$ & 05 & $\begin{array}{l}\text { reserva } \\
\text { social }\end{array}$ & $\begin{array}{c}\text { Edital } \\
\mathrm{n}^{\circ} 10 / 2009\end{array}$ \\
\hline $\begin{array}{l}\text { Universidade de Brasília } \\
\text { (UnB) }\end{array}$ & 10 & $\begin{array}{l}\text { reserva } \\
\text { racial }\end{array}$ & $\begin{array}{c}\text { Plano de } \\
\text { Metas e } \\
\text { Integração } \\
\text { Social, Étnica } \\
\text { e Racial }\end{array}$ \\
\hline $\begin{array}{l}\text { Universidade Federal do } \\
\text { Pampa (Unipampa) }\end{array}$ & 23 & $\begin{array}{c}\text { reserva } \\
\text { sociorracial }\end{array}$ & $\begin{array}{c}\text { Edital } \\
\mathrm{n}^{\circ} 82 / 09\end{array}$ \\
\hline $\begin{array}{l}\text { Universidade Federal do } \\
\text { Vale do São Francisco } \\
\text { (Univasf) }\end{array}$ & 04 & $\begin{array}{l}\text { reserva } \\
\text { social }\end{array}$ & $\begin{array}{c}\text { Edital } \\
\mathrm{n}^{\mathrm{o}} 17 / 2009\end{array}$ \\
\hline $\begin{array}{l}\text { Universidade } \\
\text { Tecnológica Federal do } \\
\text { Paraná (UTFPR) }\end{array}$ & 09 & $\begin{array}{l}\text { reserva } \\
\text { social }\end{array}$ & $\begin{array}{l}\text { Deliberação } \\
\text { no } 12 / 2007\end{array}$ \\
\hline
\end{tabular}

Fonte: Ordenamentos das Ifes, organizado por Portes e Sousa.

\section{Da exposição e análises dos dados}

Apresentamos, primeiramente, um panorama geral das ações afirmativas, em seguida, as descrições e análises das seis categorias utilizadas e, por fim, uma discussão a respeito das políticas de assistência/ permanência. Ressaltamos, para melhor entendimento, que as categorias explicativas (reserva de vagas, reserva sociorracial, reserva social, reserva racial, bônus, bônus social, bônus sociorracial e processo seletivo específico) são construções efetuadas por nós a partir dos ordenamentos consultados, para que pudéssemos realizar as diferentes classificações que seguem.

\subsection{As diferentes políticas/ações afirmativas}

Dados do Grupo de Estudos Multidisciplinares da Ação Afirmativa (Gemaa) apresentados em artigo de Feres Júnior (2008) mostram que, em 2008, ano de publicação do referido artigo, 57 Instituições Públicas de Educação Superior (Ipes) adotaram programas de ação afirmativa, 
ou seja, o estudo do Gemaa abordou universidades federais, estaduais e municipais. Já em nosso trabalho, realizado no segundo semestre de 2009, priorizamos apenas as instituições federais de ensino superior e encontramos os seguintes números, após o levantamento efetivado junto a 59 universidades federais:

- $64 \%$ das universidades adotam políticas/ações afirmativas;

- $36 \%$ não as adotam.

Entre as universidades que utilizam políticas/ações afirmativas $(\mathrm{n}=38)$ como forma de ingresso em seus diferentes cursos, notamos que:

- $73 \%$ adotam políticas/ações afirmativas na forma de reserva de vagas;

- 24\%, na forma de bônus;

- $3 \%$ realizam processos seletivos específicos para indígenas.

Entre aquelas que optam pela forma de reserva de vagas $(n=28)$, observamos que:

- $57 \%$ adotam a reserva sociorracial;

- $32 \%$, a reserva social;

- $11 \%$, a reserva racial.

Entre as universidades que adotam políticas/ações afirmativas na forma de bônus $(n=9)$ :

- $78 \%$ oferecem bônus social;

- $22 \%$, bônus sociorracial.

Do total das Ifes que adotam as políticas/ações afirmativas $(n=38)$, temos que:

- $74 \%$ não citam na documentação analisada a questão da permanência/assistência;

- 26\% mencionam a permanência/assistência.

Podemos observar pelos dados expostos que é significativo o número de universidades que se sensibilizaram com os discursos sobre a questão tratada. Essa movimentação se fez ouvir no interior dos conselhos universitários e parece contar também com o apoio dos reitores, mesmo que possamos identificar, ainda, a resistência de um conjunto importante de universidades em ofertar políticas/ações afirmativas da ordem de um terço. Mas, ao que tudo indica, poderão ceder às pressões internas e externas para implantá-las no futuro.

Observamos ainda pelos dados que as modalidades de políticas/ ações afirmativas não são as mesmas e comportam singularidades que 
parecem obedecer às discussões intensas produzidas nos meios universitários e na própria mídia de massa, ao verificarmos que apenas 8,0\% daquelas que oferecem as políticas/ações afirmativas $(n=38)$ optaram pela reserva racial.

Se, por um lado, as universidades cederam aos argumentos favoráveis à implantação das políticas/ações afirmativas, por outro, preservaram-se ao não adotar uma política fundada exclusivamente no conceito de raça, revelando uma clara opção por um modelo misto, o sociorracial, da ordem de 89\% (somadas aqui a reserva sociorracial e a social), mais ao gosto de todos, modelo que enfrenta menos resistência nos meios acadêmicos e científicos. Contudo, as políticas/ações afirmativas para facilitar o ingresso no ensino superior público foram pensadas, de início, como podemos perceber no discurso da delegação brasileira na Conferência de Durban, em beneficio da comunidade negra, devido aos números que denunciavam o lugar periférico que ela ocupava e, a nosso ver, ocupa na sociedade brasileira. Mas as instituições públicas de ensino superior gozam de autonomia administrativa, principalmente no que se refere à tomada de decisões, direito democrático que permite às universidades decidirem por adotar ou não as políticas/ações afirmativas. Assim, nesse jogo político, executado com dados da realidade, sentimentos e desejos, o modelo de políticas/ações afirmativas de caráter sociorracial e social parece ser o vitorioso.

\subsubsection{Reserva social}

A reserva social $(01,02,03,04,05,06,07,08,09)^{3}$ se destina a candidatos egressos de escolas públicas, e o percentual de vagas disponibilizadas por essa política varia entre $20 \%$ e $50 \%$. Contudo, o entendimento sobre quais são os estudantes oriundos de escolas públicas que têm direito a concorrer pela política de reserva de vagas é diferente, pois cada instituição estabelece em sua legislação o perfil dos candidatos.

No que se refere aos objetivos para a implementação das ações afirmativas, vejamos os exemplos:

a) "Estabelecer um sistema de inclusão social" - Resolução nº 23/2009 do Conselho de Ensino, Pesquisa e Extensão da Universidade Federal do Espírito Santo (Ufes).

b) "Considerando a necessidade de democratizar o acesso ao ensino público no país, especialmente aos alunos oriundos da escola pública" - Deliberação no 12/2007 do Conselho Universitário da Universidade Tecnológica Federal do Paraná (UTFPR).

c) "A necessidade de contribuir para a democratização do ensino superior, assegurando particularmente a entrada de egressos de escolas públicas e de setores historicamente discriminados." - Resolução no 3.270, de 13 de fevereiro de 2008, do Conselho de Ensino, Pesquisa e Extensão da Universidade Federal de Ouro Preto (Ufop).
${ }^{3}$ Números correspondentes à identificação das universidades, utilizados na construção do Quadro1 - Instituições Federais de Ensino Superior que possuem ações afirmativas. 
d) "Instituir o Programa de Ação Afirmativa de Ingresso no Ensino Superior [...] visando ampliar os níveis de inclusão social e de democratização do ingresso no ensino." - Resolução no 20/2008 do Conselho Universitário da Universidade Federal de Uberlândia (UFU).

Percebemos que a preocupação central é a democratização do ensino superior, incluir aqueles que por diferentes motivos ainda estão fora das universidades públicas, uma vez que os estudantes provenientes da classe operária, afirma Romanelli (2007), não fazem parte dos quadros dessas instituições gratuitas e de prestígio, ressalvadas as exceções. Há uma improbabilidade estatística da longevidade escolar em famílias de camadas populares, apontada por Viana (2007). Sabe-se que nos cursos de menos prestígio social, como as licenciaturas, a participação de estudantes dos meios populares e egressos de escolas públicas ocorre com mais representatividade, comparada à dos cursos mais concorridos, pois nos mais seletivos, como Medicina, Engenharia, Ciência da Computação, Comunicação Social, Direito, o acesso se restringe aos herdeiros culturais que possuem um elevado capital escolar e cultural (Portes, 2007). Nesse sentido, entendemos que as ações afirmativas sob a forma de cotas e bônus, que visam à democratização do espaço universitário, devem abranger todos os cursos, inclusive os mais seletivos. O fato de se discutir o acesso de algumas minorias, algo que até então não frequentava as discussões do governo e das próprias instituições de ensino superior, pode ser considerado um avanço. Porém, é necessária a criação de programas de assistência aos estudantes que se utilizam das promoções de ingresso e conseguem chegar a esse nível de ensino, para que seja garantida sua permanência após a entrada e, assim, se possa falar em democratização das universidades públicas.

Dessa forma, a Ufop assegura, por intermédio da Resolução no 3.270/2008, a entrada de egressos de escolas públicas e de setores historicamente discriminados. Todavia, a reserva de vagas identificada é apenas para estudantes oriundos de escolas públicas - que cursaram integralmente o ensino médio nessas instituições. A Ufop destina 30\% das vagas para esse segmento e se compromete com a melhoria das condições de entrada e permanência dos estudantes.

A UFU leva em consideração alguns pontos para a fundamentação de sua política de reserva de vagas, como os altos índices de exclusão social e as dificuldades encontradas pelos estudantes provenientes de escola pública para ter acesso ao ensino superior público. Além disso, entende que existe uma autoexclusão desses alunos, pois eles se consideram despreparados para enfrentar o processo seletivo nos moldes comuns, como também vêm mostrando as pesquisas. Para Braga et al. (s/d, p. 17), "são poucos os candidatos que desafiam a hierarquia não escrita dos cursos e carreiras". Assim, a UFU reconhece a necessidade de políticas que levem a inclusão social e a democratização do acesso e da permanência na universidade. Ao estudar um segmento específico das classes médias, as menos favorecidas econômica e culturalmente, Romanelli (2007) afirma 
que a escolha do curso resulta do interesse do aluno por determinada área de conhecimento, pelo reconhecimento da profissão no mercado de trabalho, pelo conhecimento acerca da instituição e da possibilidade de receber ou não suporte financeiro da família. O autor cita Lahire (1997), que se refere ao capital cultural e escolar desses alunos, reconhecido pelos próprios estudantes como insuficiente para concorrer ao vestibular de instituições públicas de ensino superior.

Nesse sentido, chamamos a atenção para os estudantes das camadas populares que percorreram todo o ensino fundamental e o médio em escolas públicas e disputam vagas na universidade com estudantes provenientes da rede particular de ensino, que, como é conhecido, prepara estrategicamente para o concurso do vestibular.

Acreditamos que a reserva de vagas ou o bônus se constitui em um incentivo aos estudantes, principalmente os das camadas populares, que se autoexcluem do processo seletivo. Mas alertamos para a necessidade de assisti-los, pois o sucesso escolar, para os alunos que não podem contar com apoio financeiro de seus familiares, não se efetiva somente com a entrada na universidade. O ingresso não é sinônimo de permanência, e esta não é sinônimo de sucesso escolar e de bons rendimentos. Para alguns estudantes, é necessária a troca de horas de estudo por horas de trabalho, a fim de que façam frente às necessidades pessoais e financeiras para, só assim, chegarem à conclusão do curso superior.

Quanto às políticas implementadas, tomemos o exemplo da Universidade Federal do Piauí (UFPI), que, de acordo com o Edital $n^{\circ}$ 19/2009 do processo seletivo desse mesmo ano, reserva vagas aos candidatos que cursaram a educação básica (ensino fundamental e médio) integral e exclusivamente em escolas públicas, ou seja, pretende beneficiar aqueles que não passaram em nenhum momento de sua trajetória escolar pela rede particular de ensino.

Cabe ressaltar ainda o caso da Ufes, que, segundo a Resolução $n^{\circ}$ 23/2009 do Conselho de Pesquisa e Extensão, une ao quesito oriundo de escola pública a renda familiar mínima. Assim, para concorrer às ações de entrada dessa universidade, que reserva $40 \%$ das vagas, o candidato deve ter cursado no mínimo as quatro séries do ensino fundamental e todo o ensino médio em escolas públicas do Brasil e possuir renda familiar de até sete salários mínimos mensais. Podemos inferir, nesse caso, que a preocupação da Ufes é de que apenas alunos egressos de escolas públicas e com o limite de renda imposto acima sejam beneficiados pela reserva de vagas, de modo a não contemplar aqueles que, de alguma forma, já são cultural e economicamente favorecidos.

\subsubsection{Reserva racial}

A reserva racial $(10,11,12)$ beneficia candidatos com base na etnia e em características fenotípicas, como tom da pele, tipo de traços físicos, cabelos e outros aspectos; as vagas reservadas variam de $5 \%$ a $20 \%$. Como acontece na reserva social, existem peculiaridades de uma 
instituição para outra, mas nesta categoria, em especial, os candidatos devem autodeclarar-se como pertencentes a determinada etnia, possuir traços fenotípicos do grupo racial declarado e, em alguns casos, passar por uma banca de validação ou comissão que tenta solucionar possíveis mal-entendidos, ou seja, a autodeclaração nem sempre é aceita como verdadeira - fato bastante criticado pelos defensores e opositores das cotas. Assim, o pertencimento ao grupo racial declarado, algo subjetivo e de difícil definição, principalmente devido à mestiçagem da nossa população, é validado por pessoas que têm nas mãos o poder de afirmar quem é negro e quem não é, quem terá direito aos benefícios da ação afirmativa e quem não terá.

No caso da Universidade Federal de Tocantins (UFT), características fenotípicas não são o principal critério de avaliação, mas sim a apresentação de um documento que comprove a origem étnica do candidato: "terão direito a usufruírem do sistema de cotas os estudantes indígenas que apresentarem declaração da Funai confirmando sua origem étnica" (Resolução UFT, Consepe no 3A/2004).

As ações afirmativas para a comunidade indígena, a nosso ver, geram menos polêmica do que as em benefício dos negros e pardos. Isso talvez se deva ao fato de os indígenas representarem uma minoria na sociedade brasileira e suas características fenotípicas serem passíveis de reconhecimento, ao passo que a condição de pertencer à comunidade negra pode incluir, além de traços físicos, questões relativas à construção das identidades. Segundo Sansone (2005), a definição de quem é negro ou não branco no Brasil é, também, uma decisão política.

Na Universidade de Brasília (UnB), "os candidatos têm a opção de se identificarem como negros e, aqueles que o fizerem, disputarão vagas dentro do sistema de cotas. Quem escolher este dispositivo, será fotografado no local da inscrição" (Plano de Metas e Integração Social, Étnica e Racial da UnB). De acordo com a professora Dione Moura, relatora da Comissão de Implantação desse Plano de Metas, as fotos serão apenas para homologar a inscrição. Ela diz ter conhecimento de que haverá casos em que irmãos serão considerados pertencentes a grupos raciais distintos e afirma que a "avaliação será feita pelo fenótipo, cor da pele e características gerais da raça negra, porque esses são os fatores que levam ao preconceito". Os candidatos ao vestibular pelo sistema de cotas da UnB são obrigados a fazer a inscrição presencial, isso dificulta a participação de candidatos provenientes de locais distantes da universidade ou mesmo de fora da cidade de Brasília. Maggie (2005) comenta um artigo de Marco Chor Maio e Ricardo Ventura Santos, em que esses autores alertam a sociedade para os riscos da classificação racial e apontam o caso da Comissão da UnB, que tem o poder de homologar ou não a inscrição dos candidatos pelo sistema de cotas. Os autores questionam o poder de "peritagem racial" dado a essas pessoas, componentes da comissão, de classificar os candidatos em raças.

Já na Universidade Federal de Alagoas (Ufal), no "momento da inscrição o/a candidato/a que se autodeclarar preto/a ou pardo/a conforme 
a metodologia adotada pelo Instituto Brasileiro de Geografia e Estatística (IBGE) [...] e comprovar que cursou ou cursa o ensino médio exclusivamente e integralmente em escola pública pode optar por concorrer a cota de vagas para a população negra" (Resolução Ufal, Cepe nº 09/2004). Não identificamos, nesse caso, a instalação de uma comissão, ou banca, para a validação da autodeclaração do candidato. A Ufal, além de reservar vagas com base no caráter racial, subdivide o percentual em gêneros. Desse modo, disponibiliza 20\% das vagas de cada curso para a população negra e, desse percentual, reserva 60\% para mulheres negras e 40\% para homens negros. Nesse caso, a instituição leva em consideração dois tipos de argumentos, pois, além de beneficiar pessoas negras no geral, subdivide o percentual de forma a atender as mulheres negras. Alguns estudos de gênero demarcam diferenças substanciais entre homens e mulheres em diversos aspectos da vida social, como escolarização, mercado de trabalho e rendimentos mensais, demonstrando resquícios de um tempo em que as mulheres não tinham voz e vontades. Assim, para as mulheres negras é reservado um percentual maior de vagas, pois elas seriam discriminadas por razões raciais, ou seja, por serem negras, e pelo fato de serem mulheres.

Cabe ressaltar, quanto ao perfil do estudante que tem direito à reserva de vagas da Ufal, que ele deve pertencer ao grupo étnico negro e ter cursado o ensino médio em escolas públicas, ou seja, é uma política de caráter racial, subdividida em gêneros, mas que também faz um recorte de caráter social. Além disso, a "conclusão do ensino médio por meio dos exames gerais supletivos só poderá ser aceita como comprovação de conclusão na instituição pública se o concorrente comprovar que realizou curso preparatório em instituição pública", como se pode ver na Resolução no 09/2004 do Conselho de Ensino, Pesquisa e Extensão. A literatura do campo da Sociologia da Educação, segundo Zago (2007), aponta para uma correlação existente entre a origem social dos alunos e o sucesso ou fracasso escolar. A autora afirma que os maiores índices de analfabetismo, evasão e reprovação se encontram nas camadas populares. Assim, apontamos que o supletivo pode ser uma estratégia de reparação empreendida para não atrasar os estudos daqueles que sofreram reprovação ou mesmo para os trabalhadores-estudantes que veem nesses cursos uma forma de trabalhar e continuar os estudos a partir de circunstâncias reais. Consideramos que não beneficiar os egressos dessa modalidade de ensino é excluir esses candidatos, que em sua maioria são provenientes das camadas populares e tentam conciliar o inconciliável: trabalho e estudos (Portes; Sousa, 2009).

\subsubsection{Reserva sociorracial}

A reserva sociorracial $(13,14,15,16,17,18,19,20,21,22,23,24$, $25,26,27,28)$ se caracteriza pela junção da reserva social com a racial, ou seja, contempla sujeitos com base em aspectos sociais e características étnico-raciais. Nesta categoria, identificamos uma expansão do caráter 
social, pois, além daqueles egressos de escolas públicas, são beneficiados também candidatos com necessidades especiais.

A reserva sociorracial disponibiliza de $20 \%$ a $50 \%$ das vagas, com exceção da Universidade Federal Rural da Amazônia (Ufra), que, de acordo com o Edital 2010, tem o programa de reserva de vagas diretamente proporcional ao número de candidatos oriundos de escolas públicas inscritos no processo seletivo. Das vagas reservadas aos egressos de escolas púbicas, 20\% são destinadas aos autodeclarados pretos ou pardos e 5\% aos autodeclarados índios. Encontramos cinco Ifes que, além da reserva sociorracial, criaram vagas suplementares destinadas às comunidades indígenas e quilombolas $(24,25,26,27,28)$, ou seja, pessoas que vivem em comunidades remanescentes dos antigos quilombos.

Dentro da categoria reserva sociorracial, mais da metade das instituições designam um percentual de vagas mais elevado para candidatos negros ou pardos.

Na Universidade Federal da Bahia, são reservadas 43\% das vagas de cada curso para estudantes que fizeram todo o ensino médio e pelo menos uma série do ensino fundamental, entre a $5^{\mathrm{a}}$ e a $8^{\mathrm{a}}$, em escola pública; entretanto, esse percentual deverá ser composto de "pelo menos 85\% (oitenta e cinco por cento) de estudantes que se declarem pretos ou pardos". Além disso, "em cada curso, serão admitidos até 02 (dois) estudantes além do número de vagas estabelecido para o curso, desde que índios aldeados ou moradores das comunidades remanescentes dos quilombos, que tenham cursado da quinta série do ensino fundamental até a conclusão do ensino médio integralmente em escolas públicas e que obtenham pontuação superior ao ponto de corte na primeira fase do vestibular e não sejam eliminados na segunda fase", conforme Resolução $n^{\circ}$ 01/04 do Conselho de Ensino, Pesquisa e Extensão da Universidade Federal da Bahia.

A Universidade Federal do ABC (UFABC) "manterá a política de reserva de vagas destinando $50 \%$ do total de vagas para candidatos que tenham cursado integralmente o ensino médio em escolas públicas", de acordo com a Resolução no 32/2009 do Conselho de Ensino e Pesquisa da Universidade Federal do ABC. Contudo, do percentual de vagas reservadas, $28,3 \%$ das vagas serão destinadas para candidatos que se autodeclarem negros e pardos e 0,1\% para indígenas.

Na Universidade Federal do Maranhão (UFMA), as vagas são distribuídas por categorias: universal, escola pública, negro, especial (modalidade índio e portador de deficiência). Nesse caso, o "número de vagas ofertadas para a categoria escola pública corresponderá a 25\% (vinte e cinco por cento) do total anual, por curso", e o "número de vagas ofertadas para a categoria negro corresponderá a 25\% (vinte e cinco por cento) do total anual, por curso", como está no Edital no 95/2008, do processo seletivo de 2009 da UFMA. No caso dessa universidade, será subtraído o número de quatro vagas por curso da categoria universal, das quais serão destinadas duas para a modalidade índio e duas para portador de deficiência. 
Por fim, ressaltamos a Universidade Federal de Santa Maria (UFSM), que disponibiliza "vinte por cento das vagas nos processos seletivos [...] para estudantes das escolas públicas, em cada um dos cursos de graduação", e "até quinze por cento das vagas [...] para estudantes afro-brasileiros" (Resolução UFSM no 11/07). A UFSM também reserva vagas (5\%) para estudantes com necessidades especiais, além de oferecer vagas suplementares para estudantes indígenas.

\subsubsection{Bônus social}

Além da política de reserva de vagas, identificamos Ifes que implantaram ações afirmativas na forma de bônus, ou seja, acréscimo na nota das provas dos candidatos ao processo seletivo do vestibular. Esse bônus pode ser de caráter social ou sociorracial.

O bônus social $(29,30,33,34,35,36,38)$ beneficia estudantes egressos ou não do sistema público de ensino, além daqueles que residam fora de regiões metropolitanas. O acréscimo na nota varia entre 10\% e 15\%, de acordo com cada instituição.

Na Universidade Federal do Rio Grande do Norte (UFRN), segundo o Edital do Processo Seletivo de 2010, para ter direito ao bônus, denominado de Argumento de Inclusão, no valor de 10\%, o candidato deve ter cursado, com aprovação, na modalidade regular, os três últimos anos do ensino fundamental e todo o ensino médio na rede pública. Estudantes dessa rede que cursaram, por meio da modalidade de ensino supletivo, o fundamental e/ou o médio não serão beneficiados com o bônus.

Entendemos que tal medida visa garantir a qualidade do ensino na universidade, visto que um dos argumentos utilizados contra a implementação de ações afirmativas, para o ingresso de minorias, é um possível rebaixamento da qualidade dos cursos. Negar o bônus ao candidato que sofreu alguma reprovação implica excluir aqueles, em potencial, que não tiveram uma trajetória escolar regular e livre da reprovação, aspectos frequentemente observados no percurso estudantil de sujeitos das camadas populares. Logo, os beneficiados, em grande parte, por essas ações afirmativas seriam os alunos que possuem uma trajetória escolar semelhante à de estudantes das camadas médias que, de acordo com Nogueira (2007, p. 129), ao citar Berthelot (1993), têm uma trajetória marcada pela "precisão e a rapidez de uma flecha". Não beneficiar com o bônus candidatos oriundos da modalidade supletivo, como já discutimos anteriormente, significa excluir os estudantes que mais poderiam dele se favorecer.

\subsubsection{Bônus sociorracial}

Identificamos ainda o bônus sociorracial (31, 32), que contempla candidatos com base em características sociais e raciais. Esse tipo de bônus foi adotado em duas instituições: a Universidade Federal de Minas Gerais (UFMG) e a Universidade Federal do Rio Grande (Furg). 
A UFMG, de acordo com o Edital do Processo Seletivo de 2010, acrescenta 10\% sobre a nota dos candidatos que cursaram, com aprovação, as quatro últimas séries do ensino fundamental e todo o ensino médio em escolas públicas do Brasil; para aqueles que atendam aos requisitos citados e se autodeclarem pardos ou pretos, o bônus sobre a nota final de cada etapa é de $15 \%$.

Na Furg, a implementação do sistema de bônus, segundo a Resolução n 019/2009 do Conselho Universitário, visa atender egressos do ensino público (em nível fundamental e médio) e portadores de deficiência, além de oferecer vagas específicas para indígenas. Aos estudantes que cursaram todo o ensino médio e pelo menos dois anos, consecutivos ou não, do fundamental em escola pública, são concedidos seis acertos sobre a nota final das provas objetivas. Para aqueles que atendam aos requisitos citados e se autodeclarem negros ou pardos, são concedidos, além dos seis acertos, mais três, somando um total de nove. Aos candidatos portadores de necessidades especiais, são concedidos nove acertos no final das provas objetivas.

\subsubsection{Processo seletivo específico}

Por último, encontramos na Universidade Federal de Roraima - UFRR (37) a realização de processo seletivo específico para povos indígenas.

\subsection{As políticas de permanência}

Nos ordenamentos analisados, encontramos dez instituições (03, $07,10,14,19,24,25,26,27,28)$ que deixaram de forma explícita uma preocupação com a permanência dos estudantes que possam se beneficiar das políticas de promoção de ingresso. Contudo, cabe ressaltar que o fato de mencionarem a questão da permanência não significa perceber efetivamente a existência de políticas de assistência/permanência, e sim que essas instituições incorporam aos seus discursos mais essa categoria de análise que favorece a compreensão das possibilidades dos pobres no interior das universidades públicas federais.

Ao analisar detidamente os ordenamentos que citam a permanência, observamos que apenas quatro universidades - Universidade de Brasília (UnB), Universidade Federal de Santa Catarina (UFSC), Universidade Federal de Goiás (UFG) e Universidade Federal de Juiz de Fora (UFJF) apresentam programas efetivos de inclusão voltados para a permanência daqueles que se beneficiam das políticas de ingresso e contemplam, inclusive, diversos aspectos do contexto social dos estudantes.

Contudo, acrescentamos também a UFMG, que, mesmo não apresentando uma discussão sobre a questão da permanência nos ordenamentos consultados, relativos às ações afirmativas, tem um programa de assistência e permanência sólido que antecede à federalização da instituição. Esse programa não faz um recorte étnico-racial, ou seja, não atende exclusivamente os estudantes beneficiados pelas políticas de promoção de 
ingresso, mas atende os provenientes das camadas populares em diversos aspectos da vida universitária, pois oferece moradia, auxílio transporte, restaurante universitário, acompanhamento médico, odontológico, psicológico e pedagógico, compra de livros com descontos, bolsa manutenção, entre outros serviços. Acrescentamos o caso da UFMG por ser de nosso conhecimento devido a outras pesquisas realizadas, sendo uma delas sobre a permanência de um estudante pobre no ensino superior (Portes e Sousa, 2009) e a outra sobre a Caixa dos Pobres e a ação efetiva da assistência na permanência de estudantes pobres na universidade de Minas Gerais, atual Universidade Federal de Minas Gerais (Portes, 2003). Essas pesquisas nos possibilitaram conhecer mais profundamente as práticas voltadas para a permanência na UFMG dos estudantes provenientes de meios menos favorecidos econômica e culturalmente. Com isso, afirmamos que outras instituições podem oferecer efetivos programas de assistência/permanência, porém, por não constarem na documentação analisada e fugirem do conhecimento dos pesquisadores, não aparecem.

Feitas as colocações acima, vejamos o caso da UnB, que, no seu Plano de Metas e Integração Social, Étnica e Racial, apresenta os três pontos básicos do programa de ação afirmativa da instituição: o acesso de negros e indígenas, a permanência dos estudantes que ingressam e o programa de apoio ao ensino público do Distrito Federal. Vemos aqui que a "permanência do estudante que ingressa, via política de ação afirmativa", é priorizada. Como mencionamos na introdução deste trabalho, Carvalho (2005) nos ajuda a compreender as políticas de permanência da UnB e afirma que os alunos negros de baixa renda recebem bolsa e têm preferência nos alojamentos. Quanto aos estudantes indígenas, a Fundação Nacional do Índio (Funai) disponibiliza bolsa e alojamento.

Já na UFSC, de acordo com a Resolução nº 008/2007, que trata do estabelecimento das ações afirmativas, estas têm início na preparação dos candidatos ao vestibular. Nesse sentido, é realizada a divulgação do programa em escolas e meios de comunicação, além da oferta de curso pré-vestibular gratuito, priorizando estudantes egressos do ensino público. Após o ingresso, o aluno recebe, quando necessário, apoio acadêmico e econômico, mediante criação e reestruturação de programas já existentes, bolsas acadêmicas e celebração de convênios com órgãos públicos e privados, tudo de modo a auxiliar a permanência. Além disso, a UFSC, de acordo com o capítulo VI da resolução citada, desenvolve "ações afirmativas para o acompanhamento da inserção socioprofissional dos alunos egressos da universidade".

Nessa mesma linha, conforme o anexo da Resolução 29/2008, foi criado o programa UFG Inclui, pelo qual se estabelecem ações de assistência antes do ingresso (com uma efetiva campanha de divulgação do programa de inclusão nos meios de comunicação e escolas) e após (com a ampliação de programas de assistência aos estudantes provenientes das camadas populares), pois acredita ser

consenso o fato de que qualquer ação que favoreça o acesso de minorias na universidade deve ser acompanhada de mecanismos consistentes de 
apoio à permanência, sejam aqueles relativos a aspectos econômicofinanceiros, sejam os referentes ao desempenho acadêmico mais especificamente. Não basta incluir, é preciso criar as condições de fato para que esses estudantes vivenciem a vida universitária em sua plenitude, assegurando a sua permanência até a conclusão do curso. (Anexo da Resolução nº 29/2008, p. 20).

Por fim, mencionamos o caso da UFJF, que, pela Resolução nº 16/2004, "institui como parte de uma política global de inclusão, que envolve o pré-ingresso, o ingresso e a permanência no ensino superior, o sistema de cotas", ou seja, nessa instituição, a discussão a respeito das cotas é intrínseca a uma "política global de inclusão", que envolve diferentes pontos da trajetória do candidato ao vestibular: o pré-ingresso, o ingresso e a permanência no ensino superior.

As demais universidades pertencentes ao grupo daquelas que citam a permanência comprometem-se a implantar programas para tal fim, tendo em vista:

a) "fortalecer ações para a permanência na universidade" - Resolução UFSCar no 011/2007;

b) "desenvolver ações visando a apoiar a permanência" - Decisão UFRGS no 134/2007;

c) "criar condições próprias de acesso, permanência e conclusão" Resolução UFU nº 20/2008;

d) "implantar um programa permanente de acompanhamento e apoio pedagógico" - Resolução UFSM nº 011/2007;

e) "melhoria das condições de entrada e permanência dos ingressantes da Ufop" - Resolução Ufop Cepe no 3.270/2008;

f) assumir "o compromisso de estabelecer uma política de permanência" - Resolução UFPA nº 3.361/2005.

Percebemos que nesses ordenamentos não existe uma preocupação em especificar qual é o entendimento da instituição sobre o que venha a ser uma política de assistência/permanência e como implantar e efetivar essas políticas.

Quando observamos e consideramos as políticas/ações de permanência/ assistência, os números mostram que apenas um terço daquelas universidades que as oferecem cuidou de constar em seus ordenamentos legais essa possibilidade. Podemos notar pelos nossos dados o triunfo da "política de custo zero" visto na ampliação e na promoção dos pobres ao ensino superior, o que não é tão pouco em se tratando da história desse nível de ensino no Brasil. Mas, por outro lado, as condições de permanência daqueles privilegiados pelas políticas de acesso não parecem ser a preocupação das forças mobilizadas na questão, produzindo a ilusão de que o simples ingresso possa ser um fator de democratização do ensino superior, quando se sabe, desde muito, que o acesso ao saber implica condições objetivas e subjetivas que permitam aos diferentes sujeitos sociais se expressarem e ampliarem suas possibilidades culturais e cognitivas. 
Em um passado recente, as pesquisas mostraram os equívocos da educação compensatória, voltada para suprir supostas deficiências, de caráter cultural, de crianças das camadas populares. Essas políticas não pretendiam agir sobre o contexto social como um todo, mas sim sobre as vítimas dele. De acordo com Soares (1996, p. 13), os defensores dessa ideologia baseada na deficiência cultural acreditavam na "superioridade do contexto cultural das classes dominantes" em comparação com o das camadas populares; para essa ideologia, a causa do fracasso escolar seria o aluno "portador de déficits socioculturais", e caberia à escola compensar as deficiências das camadas populares. As críticas à educação compensatória se organizaram no sentido de criticar justamente essa falta de ação sobre o verdadeiro foco do problema por não questionar a organização e a estruturação da sociedade.

Nesse sentido, ressaltamos a precariedade de políticas que visam, ao modo das compensatórias, reconhecer os estudantes de escolas públicas, majoritariamente pertencentes às camadas populares e a grupos étnicos excluídos socialmente, com a promoção de seu ingresso na universidade, sem estabelecer critérios objetivos que possam assegurar condições básicas de permanência, ou seja, são dadas as oportunidades, mas, se eles não permanecerem no ensino superior, a culpa é de cada um, bem ao gosto da ideologia do dom.

O Estado parece se eximir de qualquer responsabilidade nesse sentido. Segundo Paula (2004, p. 233), o próprio projeto de lei das cotas, encaminhado pelo Governo Lula em 2004 ao Congresso Nacional, não contemplava aspectos relacionados à manutenção dos estudantes das camadas populares na universidade. Assim, de acordo com ela, "procura-se resolver o problema do acesso, mas não se garante a permanência".

Essa posição de "cada coisa a seu tempo" parece, mais uma vez, distanciar o Estado, como historicamente vem acontecendo, das necessárias políticas de permanência para os estudantes pobres no interior das universidades públicas.

\section{Considerações finais}

Após os dados expostos e a partir das análises, efetuamos um esforço de interpretação final, condensado nas seguintes considerações explicativas:

1) a existência das ações afirmativas é uma realidade nas universidades federais brasileiras. Aproximadamente dois terços das Ifes implantaram políticas/ações afirmativas em benefício dos mais necessitados, principalmente daqueles provenientes das escolas públicas, em um claro e importante esforço de ampliação da participação de diferentes sujeitos sociais no ensino superior público federal;

2) as políticas/ações afirmativas adotadas pelas universidades apresentam divergências e comportam singularidades no que diz respeito ao tipo, número e beneficiados. Essas diferenças são construídas no jogo de forças estabelecido em cada realidade (bônus, cotas, reservas, processos 
seletivos específicos etc.). Contudo, percebemos que as universidades, em sua maioria, adotam políticas/ações afirmativas de caráter social, beneficiando principalmente estudantes de escola pública;

3) os ordenamentos legais das universidades que oferecem políticas/ ações afirmativas comportam fórmulas variadas e complexas que podem impossibilitar o entendimento daqueles que mais poderiam se beneficiar dessas ações. Deparamo-nos com cálculos que não facilitam uma comunicação e um direto entendimento da mensagem que as universidades querem veicular. Eles requerem interpretação especializada;

4) os dados apresentados parecem mostrar que as políticas de permanência/assistência só figuram como prioridade em um conjunto restrito de ordenamentos consultados em função dos custos econômicos necessários para suas implantações. O discurso sobre as políticas de permanência/assistência não parece ter uma forte reverberação nem na sociedade nem nas universidades. O barulho efetuado sobre as "cotas" silencia a necessidade das políticas de permanência;

5) os dados indicam, por fim, um afastamento preocupante do Estado no que diz respeito às políticas de permanência/assistência aos beneficiados pelas políticas/ações afirmativas, revelando que essas questões não parecem ser faces de uma mesma moeda, entregando os sujeitos à própria sorte ou a iniciativas frouxas, temporárias, que não oferecem segurança aos estudantes, de cunho assistencialista do tipo "vale refeição", colocadas à disposição dos estudantes pobres. Esses efeitos podem ser mais perversos ainda quando se observa um forte movimento de interiorização da oferta do ensino superior público federal.

\section{Referências bibliográficas}

ALMEIDA, Wilson Mesquita de. Estudantes com desvantagens econômicas e educacionais e fruição da universidade. Caderno $C R H$, Salvador, v. 20, n. 49, p. 35-46, jan./abr. 2007.

AZEVEDO, Thales de. As elites de cor numa cidade brasileira: um estudo de ascensão social \& classes sociais e grupos de prestígio. 2. ed. Salvador: EDUFBA, 1996. 186 p.

BENJAMIN, César. Tortuosos caminhos. In: FRY, Peter et al. (Org.). Divisões perigosas: políticas raciais no Brasil contemporâneo. Rio de Janeiro: Civilização Brasileira, 2007. p. 27-33.

BRAGA, Mauro Mendes; PEIXOTO, Maria Carmo Lacerda; BOGUTCHI, Tânia Fernandes. A demanda por vagas no ensino superior: análise dos vestibulares da UFMG na década de 90. s/d. Disponível em: < http:// www.anped.org.br/reunioes/23/textos/ > . Acesso em: 2 ago. 2009. 
CARVALHO, José Jorge. Inclusão étnica e racial no ensino superior: um desafio para as universidades brasileiras. 2005. Disponível em: < http:// www.unb.br/ics/dan/>. Acesso em: 2 ago. 2009.

CARVALHO, José Jorge. Ações afirmativas para negros na pós-graduação, nas bolsas de pesquisa e nos concursos para professores universitários como resposta ao racismo acadêmico. In: SILVA, Petronilha Beatriz Gonçalves; SILVÉRIO, Valter Roberto (Org.). Educação e ações afirmativas: entre a injustiça simbólica e a injustiça econômica. Brasília: Instituto Nacional de Estudos e Pesquisas Educacionais Anísio Teixeira, 2003.

p. 161-190.

DOMINGUES, Petrônio. Ações afirmativas para negros no Brasil: o início de uma reparação histórica. Revista Brasileira de Educação, São Paulo, n. 29, p. 164-176, maio/ago. 2005.

FERES JÚNIOR, João. Ação afirmativa: política pública e opinião. Sinais Sociais. Rio de Janeiro, v. 3, n. 8, p. 38-77, set./dez. 2008.

GOLDEMBERG, José; DURHAM, Eunice Ribeiro. Cotas nas universidades públicas. In: FRY, Peter et al. (Org.). Divisões perigosas: políticas raciais no Brasil contemporâneo. Rio de Janeiro: Civilização Brasileira, 2007. p. 167-172.

GOMES, Nilma Lino. Ações afirmativas e cotas para a população negra: a construção da igualdade racional na sociedade brasileira. Revista Outro Olhar, 2005. Disponível em: < http://www.arnaldogodoy.com. br/2009/atuacao_educacao_publicacoes.html >. Acesso em: 5 ago. 2009.

GUIMARÃES, Antonio Sérgio Alfredo. Acesso de negros às universidades públicas. Cadernos de Pesquisa, São Paulo, n. 118, p. 247-268, mar. 2003.

LACERDA, Wânia Maria Guimarães. Famílias e filhos na construção de trajetórias escolares pouco prováveis: o caso dos iteanos. Tese (Doutorado em Educação) - Universidade Federal Fluminense (UFF), Rio de Janeiro, 2006.

MAGGIE, Yvonne. Políticas de cotas e o vestibular da UnB ou a marca que cria sociedades divididas. Horizontes Antropológicos. Porto Alegre, v. 11, n. 23, p. 286-291, jan./jun. 2005.

MAGGIE, Yvonne; FRY, Peter Henry. O debate que não houve. Enfoques online, Rio de Janeiro, v. 1, n. 1, dez. 2002. Disponível em: < http:// www.enfoques.ifcs.ufrj.br/>. Acesso em: 2 ago. 2009. 
MAIO, Marcos Chor; SANTOS, Ricardo Ventura. Cotas e racismo. In: FRY, Peter Henry et al. (Org.). Divisões perigosas: políticas raciais no Brasil contemporâneo. Rio de Janeiro: Civilização Brasileira, 2007. p. 161-165.

MOEHLECKE, Sabrina. Ação afirmativa: história e debates no Brasil. Cadernos de Pesquisa. São Paulo, n. 117, p. 197-217, nov. 2002.

MUNANGA, Kabengele. Ação afirmativa em beneficio da população negra. Universidade e Sociedade. Brasília, v. 1, n. 1, p. 46-52, 2003.

NOGUEIRA, Maria Alice. A construção da excelência escolar. Um estudo de trajetórias feito com estudantes universitários provenientes das camadas médias intelectualizadas. In: NOGUEIRA, Maria Alice; ROMANELLI, Geraldo; ZAGO, Nadir (Org.). Família e escola. Trajetórias de escolarização em camadas médias e populares. Petrópolis: Vozes, 2007. p. 126-154.

OLIVEN, Arabela Campos. Ações afirmativas, relações raciais e políticas de cotas nas universidades: uma comparação entre os Estados Unidos e o Brasil. Revista Brasileira de Educação, Porto Alegre, v. 30, n. 1, p. 29-51, 2007.

PAULA, Maria de Fátima Costa de. A política de cotas do governo Lula: opção real pela democratização do ensino superior ou medida compensatória com fins eleitoreiros? Educação em Revista, Belo Horizonte, v. 1, n. 40, p. 231-236, dez. 2004.

PIOTTO, Débora Cristina. As exceções e suas regras: estudantes das camadas populares em uma universidade pública. 2007. Tese (Doutorado em Psicologia) - Programa de Pós-Graduação em Psicologia, Universidade de São Paulo, São Paulo, 2007.

. Trajetórias escolares prolongadas nas camadas populares. Cadernos de Pesquisa, São Paulo, v. 38, n. 135, p. 701-707, dez. 2008.

PENA, Sérgio. Ciências, bruxas e raças. In: FRY, Peter Henry et al. (Org.). Divisões perigosas: políticas raciais no Brasil contemporâneo. Rio de Janeiro: Civilização Brasileira, 2007. p. 43-47.

PORTES, Écio Antônio. Trajetórias e estratégias escolares do universitário das camadas populares. 1993. Dissertação (Mestrado em Educação) - Faculdade de Educação, Universidade Federal de Minas Gerais, Belo Horizonte, 1993.

. Estratégias escolares do universitário das camadas populares: a insubordinação aos determinantes. In: PAIVA, Aparecida; SOARES, Magda (Org.). Universidade, cultura e conhecimento. A educação pesquisa a UFMG. Belo Horizonte: FAE/UFMG, 1998. p. 251-277. 
PORTES, Écio Antônio. Trajetórias escolares e vida acadêmica do estudante pobre da UFMG - um estudo a partir de cinco casos. 2001. Tese (Doutorado em Educação) - Faculdade de Educação, Universidade Federal de Minas Gerais, Belo Horizonte, 2001.

. A caixa dos pobres - a ação efetiva da assistência na permanência de estudantes pobres na Universidade de Minas Gerais (UMG): 1932-1935. Cadernos de História da Educação, Uberlândia, v. 1, n. 2, p. 29-38, jan./dez. 2003.

O estudante pobre na Universidade Federal de Minas Gerais: uma abordagem histórica. Educação em Revista, Belo Horizonte, v. 41, p. 111-133, 2005.

O trabalho escolar das famílias populares. In: NOGUEIRA, Maria Alice; ROMANELLI, Geraldo; ZAGO, Nadir (Org.). Família e escola. Trajetórias de escolarização em camadas médias e populares. Petrópolis: Vozes, 2000. p. 61-80.

PORTES, Écio Antônio; CRUZ, Ricardo Alexandre da. Trajetórias e estratégias sociais e escolares do pardo José Rubino de Oliveira (18371891): da selaria em Sorocaba às arcadas jurídicas do Largo de São Francisco, São Paulo. In: PEREIRA, Lúcia Helena Pena; OLIVEIRA, Wanderley Cardoso (Org.). Práticas educativas: discursos e produção de saberes. Rio de Janeiro: E-papers, 2007. p. 147-169.

PORTES, Écio Antônio; SOUSA, Letícia Pereira de. Do lado bom da barreira: trajetórias e estratégias sociais e escolares de Raymundo Augusto da Silva Maia (1900-1990). In: CONGRESSO DE PESQUISA E ENSINO EM HISTÓRIA DA EDUCAÇÃO EM MINAS GERAIS, 5., 2009, Anais... Montes Claros: Unimontes, 2009, v. 1, p. 1-15.

ROMANELLI, Geraldo. Famílias de camadas médias e escolarização dos filhos. O estudante-trabalhador. In: NOGUEIRA, Maria Alice; ROMANELLI, Geraldo; ZAGO, Nadir (Org.). Família e escola. Trajetórias de escolarização em camadas médias e populares. Petrópolis: Vozes, 2007. p. 100-123.

SANSONE, Livio. O bebê e a água do banho? A ação afirmativa continua importante, não obstante os erros da UNB! Horizontes Antropológicos, Porto Alegre, v. 11, n. 23, p. 251-254, jan./jun. 2005.

SOARES, Magda. Linguagem e escola: uma perspectiva social. 14. ed. São Paulo: Ática, 1996.

SOUZA e SILVA, Jailson de. "Por que uns e não outros?" Caminhada de estudantes da Maré para a universidade. 1999. Tese (Doutorado em 
Educação) - Pontifícia Universidade Católica do Rio de Janeiro, Rio de Janeiro, 1999.

TRAGTENBERG, Marcelo Henrique. Um olhar de branco sobre as ações afirmativas. Revista Espaço Acadêmico, Maringá, v. 2, n. 13, 2002. Disponível em: < http://www.espacoacademico.com.br/013/13cmtrag. htm>. Acesso em: 15 set. 2010.

A luta contra o racismo no Brasil e o movimento docente. Universidade e Sociedade, Brasília, v. 1, n. 1, p. 19-28, 2003.

VIANA, Maria José Braga. Longevidade escolar em famílias de camadas populares: algumas condições de possibilidade. 1998. Tese (Doutorado em Educação) - Faculdade de Educação da Universidade Federal de Minas Gerais, Belo Horizonte, 1998.

Longevidade escolar em famílias de camadas populares: algumas condições de possibilidade. In: NOGUEIRA, Maria Alice; ROMANELLI, Geraldo; ZAGO, Nadir (Org.). Família e escola: trajetórias de escolarização em camadas médias e populares. Petrópolis: Vozes, 2007. p. 45-60.

ZAGO, Nadir. Do acesso à permanência no ensino superior: percursos de estudantes universitários de camadas populares. Revista Brasileira de Educação, Rio de Janeiro, v. 11, n. 32, p. 226-237, maio/ago. 2006.

Processos de escolarização nos meios populares - As contradições da obrigatoriedade escolar. In: NOGUEIRA, Maria Alice; ROMANELLI, Geraldo; ZAGO, Nadir (Org.). Família e escola: trajetórias de escolarização em camadas médias e populares. Petrópolis: Vozes, 2007. p. 18-43.

Letícia Pereira de Sousa é mestranda do Programa de Pós-Graduação Processos Socioeducativos e Práticas Escolares da Universidade Federal de São João Del Rei (UFSJ).

pedagogaleticia@gmail.com

Écio Antônio Portes, doutor em educação pela Universidade Federal de Minas Gerais (UFMG), é professor adjunto da Universidade Federal de São João del-Rei e do Programa de Pós-Graduação Processos Socioeducativos e Práticas Escolares da mesma universidade.

eaportes@gmail.com

Recebido em 20 de abril de 2011.

Aprovado em 29 de setembro de 2011. 